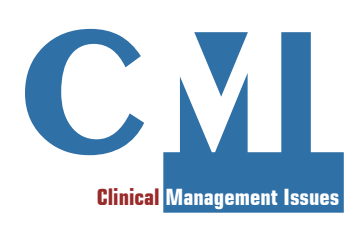

\title{
Post-angiography Acute Kidney Injury
}

L'insufficienza renale acuta da mezzo di contrasto

CMI 2018; 12(1): 63-66

https://doi.org/10.7175/cmi.v12i1.1371

\section{INTRODUCTION}

The association of a decrease in glomerular filtration rate following the administration of iodinated contrast was first described over 60 years ago [1]. The name has changed from contrast-induced nephropathy (CIN) to contrast-associated acute kidney injury (CA-AKI) to post-angiography acute kidney injury (PA-AKI), reflecting an ongoing controversy regarding the association. Since the original publication, over 1700 publications have documented this association, attempted to unravel the pathophysiologic mechanism, described the short and long-term consequences, and advised practitioners on how to prevent this association. The most common definition is an absolute increase in serum creatinine of $0.5 \mathrm{mg} / \mathrm{dl}$ or a relative increase of $25 \%$ compared to baseline that occurs over the 48-72 hours following exposure to contrast. However, many controversies remain. Guidelines from the major groups using iodinated contrast have been published and revised over the years $[2,3]$. In this brief editorial, we will review the three major tenets of these guidelines.

\section{IDENTIFY PATIENTS MOST AT RISK FOR DEVELOPING PA-AKI}

It is generally agreed that not all patients are at equal risk for PA-AKI. Figure 1 describes the pathogenesis of this form of AKI and divides it between patient-related factors and procedure-related factors.

Central to the heightened risk of this form of AKI is a vulnerable kidney. The kidney may be vulnerable because of hemodynamic alterations that either decrease blood flow (for example congestive heart failure) or perfusion pressure (hypotension), and/or impair the renal vasculature's ability to respond to contrast-induced decreases in blood flow (for example, renal insufficiency, diabetes) or drugs such as nonsteroidal antiinflammatory drugs (NSAIDs) and reninangiotensin-aldosterone system (RAAS) inhibitors. Chronic kidney disease is associated with both vascular changes and decreases in renal reserve that also make the kidney more vulnerable to subsequent injury.

A number of risk models have been presented to enable anticipation of kidney injury and to focus prophylactic efforts on those more in danger of developing PAAKI. In cardiology, the most widely used
${ }^{1}$ Professor of Medicine,

Larner College of Medicine, University of Vermont
Corresponding author Richard Solomon MD, FASN, FACP, Professor of Medicine Larner College of Medicine University of Vermont richard.solomon@uvmhealth.org

Received: 10 September 2018 Accepted: 18 September 2018 Published: 25 September 2018 
Figure 1. Model of post-angiography acute kidney injury (PA-AKI) pathogenesis that emphasizes the factors that make the kidney vulnerable to contrast. How contrast gets into body (IV or IA) doesn't alter how it gets to the kidney.

ROS = reacting oxygen species

Figure 2. Algorithm for managing patients undergoing exposure to contrast media.

$\mathrm{ACE}$ inhibitors = angiotensin-convertingenzyme inhibitors; $\mathrm{ARBs}=$ angiotensin receptor blockers; NSAIDs = nonsteroidal anti-inflammatory drugs

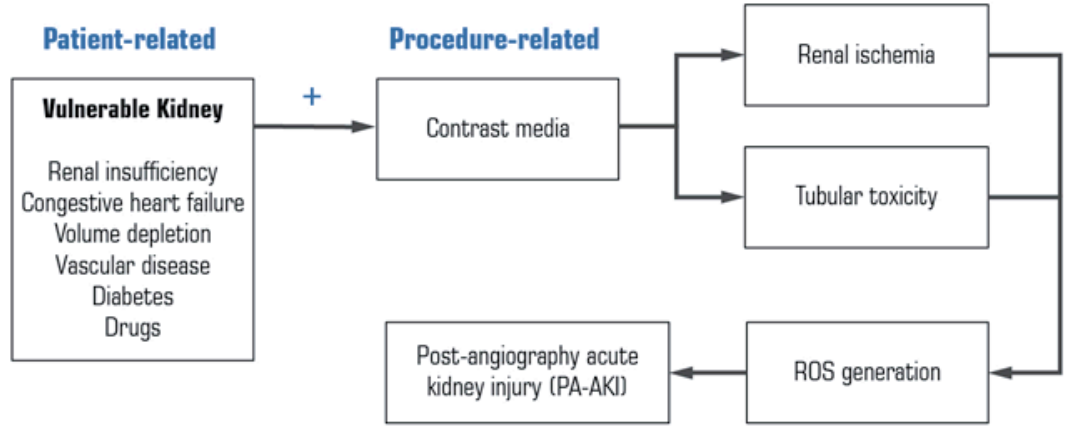

risk model uses a small number of patientand procedure-related factors to divide $\mathrm{pa}^{-}$ tients into 4 categories of risk [4]. The categories are not only predictive of AKI but also the need for dialysis and in-hospital mortality. Patients in the 2 highest risk categories are targeted for specific prophylactic interventions (see below).

\section{REDUCE THE AMOUNT OF CONTRAST ADMINISTERED}

The evidence from animal and in vitro studies suggests that iodinated contrast is directly nephrotoxic (see Figure 1) [5]. Review of large patient databases indicates that patients who receive more contrast have a higher incidence of AKI [6]. Therefore, another recommendation in the guidelines points to using as little contrast as necessary. This includes consideration of other imaging techniques that don't require use of contrast. There have also been a number of attempts to diminish the volume of contrast administered using pressure sensitive manifolds [7], automatic injectors [8], or coronary si- nus removal of contrast [9]. Hemodialysis immediately after contrast administration has also been proposed [10]. While many of these maneuvers do decrease the amount of contrast administered, the evidence that the incidence of AKI is also reduced is not compelling.

\section{PROVIDE ADEQUATE FLUID INTAKE}

There are many strategies to minimize the risk of PA-AKI, but the only consensus involves the use of fluids to induce a high urine output. There are many uncertainties about this approach, which have been studied in high-risk patients. Although intravenous fluids have been most often recommended, there is increasing evidence that oral fluids may be equally efficacious [11]. For intravenous fluids, isotonic saline and isotonic bicarbonate have been most often compared and there doesn't seem to be any difference in efficacy [12]. The timing of fluid administration has been less well studied but in general, the longer the administration the 
better the outcomes [13]. The mechanism of benefit with fluid administration is unknown, but a growing body of evidence suggests that at least part of the benefit lies in inducing a high urine flow rate. This may dilute out the contrast in the nephron and decrease the contrast contact time with the renal tubular epithelium. Additionally, high urine output seems to increase blood flow in the medulla, the most sensitive part of the kidney with respect to ischemia [14]. An algorithm for managing patients is shown in Figure 2.

\section{CONTROVERSIES}

As mentioned above, there are many areas that are hotly debated. One is whether we have grossly overestimated the impact of contrast on renal injury. Certainly, in the cardiology space, other sources of injury may be present such as hemodynamic effects and atheromatous embolic disease. While these are less of a problem in patients undergoing outpatient CT exams, no difference in the incidence of AKI between patients receiving contrast-enhanced CT and noncontrast CT has been reported [15]. These two groups have been propensity matched on the reasons for the imaging study.

\section{CONCLUSION}

Post-angiography AKI continues to be a concern and much has been learned over the past 60 years. A reasonable approach is outlined in Figure 2. Central to preparing all patients for exposure to contrast is the induction of a high urine output. High-risk patients should have an assessment of renal function in the 72 hours post-exposure to ensure that AKI has not occurred.

Funding

This article has been published without the support of sponsors.

Conflicts of Interests

The author declares he has no competing financial interests concerning the topics of this article.

\section{REFERENCES}

1. Bartels ED, Brun GC, Gammeltof A, et al. Acute anuria following intravenous pyelography in a patient with myelomatosis. Acta Med Scand 1954; 150: 297-302; https://doi. org/10.1111/j.0954-6820.1954.tb18632.x

2. Wright RS, Anderson JL, Adams CD, et al.2011 ACCF/AHA focused update of the Guidelines for the Management of Patients with Unstable Angina/Non-ST-Elevation Myocardial Infarction (updating the 2007 guideline): a report of the American College of Cardiology Foundation/American Heart Association Task Force on Practice Guidelines developed in collaboration with the American College of Emergency Physicians, Society for Cardiovascular Angiography and Interventions, and Society of Thoracic Surgeons. J Am Coll Cardiol 2011; 57: 1920-59; https://doi.org/10.1016/j.jacc.2011.02.009

3. Thomsen HS. Guidelines for contrast media from the European Society of Urogenital Radiology. AJR Am J Roentgenol 2003; 81: 1463-71; https://doi.org/10.2214/ajr.181.6.1811463

4. Mehran R, Aymong ED, Nikolsky E, et al. A simple risk score for prediction of contrast-induced nephropathy after percutaneous coronary intervention: development and initial validation. $J$ Am Coll Cardiol 2004; 44: 1393-9; https://doi.org/10.1016/S0735-1097(04)01445-7; https:// doi.org/10.1016/j.jacc.2004.06.068

5. Heyman SN, Rosen S, Khamaisi M, et al. Reactive oxygen species and the pathogenesis of radiocontrast-induced nephropathy. Invest Radiol 2010; 45: 188-95; https://doi.org/10.1097/ RLI.0b013e3181d2eed8

6. Mager A, Vaknin Assa H, Lev EI, et al. The ratio of contrast volume to glomerular filtration rate predicts outcomes after percutaneous coronary intervention for ST-segment elevation acute myocardial infarction. Catheter Cardiovasc Interv 2011; 78: 198-201; https://doi.org/10.1002/ ccd. 22828

7. Prasad A, Ortiz-Lopez C, Kaye DM, et al. The use of the AVERT system to limit contrast volume administration during peripheral angiography and intervention. Catheter Cardiovasc Interv 2015; 86: 1228-33; https://doi.org/10.1002/ccd.26155 
8. Gurm HS, Smith D, Share D, et al. Impact of automated contrast injector systems on contrast use and contrast-associated complications in patients undergoing percutaneous coronary interventions. JACC Cardiovasc Interv 2013; 6: 399-405; https://doi.org/10.1016/j. jcin.2012.11.008

9. Diab O, Helmy M, Gomaa Y, et al. Efficacy and safety of coronary sinus aspiration during coronary angiography to attenuate the risk of contrast induced acute kidney injury in predisposed patients. Circ Cardiovasc Interv 2017; 10: e004348; https://doi.org/10.1161/ CIRCINTERVENTIONS.116.004348

10. Reinecke H, Fobker M, Wellmann J, et al. A randomized controlled trial comparing hydration therapy to additional hemodialysis or $\mathrm{N}$-acetylcysteine for the prevention of contrast mediuminduced nephropathy. Clin Res Cardiol 2007; 96: 130-9; https://doi.org/10.1007/s00392-0070473-4

11. Zhang W, Zhang J, Yang B, et al. Effectiveness of oral hydration in preventing contrast-induced acute kidney injury in patients undergoing coronary angiography or intervention: a pairwise and network meta-analysis. Coron Artery Dis 2018; 29: 286-93; https://doi.org/10.1097/ MCA.0000000000000607

12. Weisbord SD, Gallagher M, Jneid H, et al. Outcomes after Angiography with Sodium Bicarbonate and Acetylcysteine. N Engl J Med 2018; 378: 603-14; https://doi.org/10.1056/ NEJMoa1710933

13. Rojkovskiy I, Solomon R. Intravenous and Oral Hydration: Approaches, Principles, and Differing Regimens. Interv Cardiol Clin 2014; 3: 393-404; https://doi.org/10.1016/j.icc1.2014.03.009

14. Heyman SN, Brezis M, Epstein FH, et al.Early renal medullary hypoxic injury from radiocontrast and indomethacin. Kidney Int 1991; 40: 632-42; https://doi.org/10.1038/ki.1991.255

15. McDonald JS, McDonald RJ, Lieske JC, et al. Risk of Acute Kidney Injury, Dialysis, and Mortality in Patients With Chronic Kidney Disease After Intravenous Contrast Material Exposure. Mayo Clin Proc 2015; 90: 1046-53; https://doi.org/10.1016/j.mayocp.2015.05.016 